\title{
Lomustine Incorporated Lipid Nanostructures Demonstrated Preferential Anticancer Properties in C6 Glioma Cell Lines with Enhanced Pharmacokinetic Profile in Mice
}

\author{
Bhabani Sankar Satapathy, ${ }^{1,{ }^{*}}$ Ladi Alik Kumar, ${ }^{2}$ Gurudutta Pattnaik ${ }^{2}$ \\ and Binapani Barik ${ }^{2}$ \\ ${ }^{1}$ School of Pharmaceutical Sciences, Siksha 'O' Anusandhan (Deemed to be University), Bhubaneswar, Odisha, India \\ ${ }^{2}$ Centurion University of Technology \& Management, Odisha, India \\ *Corresponding author: E-mail: bhabanisatapathy@soa.ac.in
}

Received: 05-30-2021

\begin{abstract}
Effective treatment of glioma still stands as a challenge in medical science. The work aims for the fabrication and evaluation of lipid based nanostructures for improved delivery of lomustine to brain tumor cells. Experimental formulations (LNLs) were developed by modified lipid layer hydration technique and evaluated for different in vitro characteristics like particle size analysis, surface charge, surface morphology, internal structure, in vitro drug loading, drug release profile etc. Anticancer potential of selected LNLs was tested in vitro on C6 glioma cell line. Electron microscopic study depicted a size of less than $50 \mathrm{~nm}$ for the selected LNLs along wirh $8.8 \%$ drug loading with a sustained drug release tendency over $48 \mathrm{~h}$ study period. Confocal microscopy revealed resonable internalization of the selected LNL in C6 cells. LNLs were found more cytotoxic than free drug and blank nanocarriers as depicted from MTT assay. The selected LNL showed improved pharmacokinetic profile both in blood and brain in the experimental mice models along with negligible hemolysis in mice blood cells. Further studies are warranted for the future translation of LNLs at clinics.
\end{abstract}

Keywords: Lomustine; lipid nanostructure; C6 glioma cells; cellular uptake; pharmacokinetic; hemolysis

\section{Introduction}

Effective treatment of brain tumor remains a challenge in medical science. Gliomas are the most common type of tumors of brain and central nervous system. ${ }^{1}$ Based on the type of primary cells along with molecular characteristics, gliomas can be of astrocytomas, ependymomas, oligodendrogliomas etc. Glioma is characterized by its uncontrolled cellular proliferation, diffused infiltration along with significant angiogenesis. ${ }^{2}$ Glioma at its fourth stage is referred to as glioblastoma multiforme, which is the most dangerous stage with poor prognosis and an average survival rate of 1-2 years. ${ }^{3}$ In spite of all the advanced medical strategies, death rate of glioma patients is increasing at an alarming rate all over the world. The treatment failures may be attributed to the delicate and sensitive characteristics of brain tissue, which limits effective application of surgery or radiation therapy; whereas presence of blood-brain barrier (BBB) further worsens the case. ${ }^{4} \mathrm{BBB}$ is the most complex, tight endothelial barrier, which strictly checks the entry of therapeutic molecules into the brain and thus stands as a serious challenge for chemotherapy. ${ }^{5,6}$ Although, many conventional anticancer drugs are available in clinical practice, but majority of them fails to maintain the desired therapeutic concentration in the brain tissue for a sufficient period of time due to their inability to pass effectively through BBB. ${ }^{7}$ Some lipophilic drugs like carmustine, temozolomide, bevacizumab etc. are being claimed to cross BBB, but shorter half-life along with severe dose related toxic effects associated with them throw additional challenges to get desired treatment outcomes. ${ }^{8,9}$ In this context, novel drug delivery strategies like nanoliposomes, nanoparticles, polymeric micelles, niosomes, dendrimers etc. have been investigated 
widely in past years to improve the efficacy of conventional chemotherapeutic agents for the treatment of glioma. ${ }^{10,11,12}$ However, till today, very few of them have been approved to be used in clinical practice. Among various types of nanocarrier platforms, nanosize lipid based vesicular carriers have been largely preferred for successful delivery of toxic chemotherapeutic drugs to brain. ${ }^{13,14}$ Due to high lipophilic nature as well as ultra small size, they fulfill the prime requisite criteria to overcome BBB to get into the brain. Phospholipid based nanostructures (NLs) are the ultra-micron size phospholipid vesicles consisting of self assembled lipid bilayers enclosing small aqueous phase in their core. ${ }^{15}$ Due to this architectural uniqueness, they act as dual platform for both hydrophobic and hydrophilic molecules. ${ }^{16}$ The hydrophobic/lipophilic agents get entrapped in the outer lipid bilayer, where as the hydrophilic agents remain encapsulated in the aqueous core. ${ }^{15} \mathrm{NLs}$ owing to their lipophilicity, biodegradability, non-immunogenicity, biocompatibility, sustained drug release property, ease of surface manipulation etc. have drawn the attention of formulation scientists as preferred drug delivery vehicles in nanomedicine based research. ${ }^{17,18}$ Due to sustained delivery of the loaded cargo as well as site-specific delivery, the dose of the cytotoxic anti-cancer drugs is expected to be reduced, which leads to better treatment outcome and fewer side effects.

Lomustine (LS) is a nitrosourea class of antineoplastic agent, which is used in the treatment of various types of malignancies, including glioma. ${ }^{19}$ It inhibits protein synthesis by causing alkylation and cross-linking in the nucleic acids (DNA/RNA). Being lipophlic in nature, it posses the capacity to cross BBB, however, its short half life and deadly side effects like severe bone marrow depression, leucopenia, etc. limits its effective use in the treatment of glioma. ${ }^{20,21}$ Thus, there is a need to develop novel strategies for the safer and effective delivery of LS to brain and thereby reducing the dose-related side effects associated with the conventional forms.

Kevin A. Harvey et al. studied anticancer properties of LS in conjunction with docosahexaenoic acid (DHA) in glioblastoma cell lines. They studied effects of LS, alone and in combination with DHA in C6 human glioblastoma cell line. ${ }^{19}$ In another study, LS nanoparticles prepared by molecular envelope technology was tested on C6 glioblastoma bearing animal model. ${ }^{21}$ Another work reported an optimized method of development of poly (d,l-lactide-coglycolide) based LS nanoparticles and investigated their anticancer potential in lung cancer cell line L132. ${ }^{22}$ However, to our knowledge, no reports are available on the anticancer potential of lomustine loaded lipid nanostructures (LNLs) on C6 glioma cells and also on their in vivo plasma/brain pharmacokinetic (PK) profile. Haemolysis assay for LNLs in mice RBC further adds novelty to the work, which is an important piece of information for safe biomedical application.
In the lieu of which, the present study aims to investigate the anticancer potential of optimized LNLs on rat glioma cells along with evaluation of both blood and brain PK profiles in experimental animal model. The LNLs were prepared by conventional method with optimization of critical manufacturing conditions to achieve the desired nanosize. Preferably, we wanted to keep the size of LNLs within a range of $50-100 \mathrm{~nm}$ to achieve effective permeation into brain as well as to escape from reticuloendothelial system. The experimental LNLs were evaluated by different in vitro techniques and the optimized formulation was tested for its in vitro anticancer effectiveness in C6 glioma cells. Further in vivo blood and brain PK study was also carried out in experimental mice to estimate the potentiality of the optimized formulation both qualitatively and quantitatively for the treatment of glioma.

\section{Materials \& Methods}

\section{1. Materials}

LS was obtained as a gift sample from Cipla laboratories (Goa, India). Cholesterol (CHL), soya-L- $\alpha$-lecithin (SL), 1,2-distearoyl-sn-glycero-3-phosphotidylethanolamine (DSPE) were procured from Merck (Mumbai, India). Chloroform, butylated hydroxyl anisole (BHA), fluorescein isothiocyanate (FITC), were purchased from Hi-media Laboratories Pvt. Ltd (Mumbai, India). 4',6-Diamidino-2-phenylindole) (DAPI) and tetrazolium dye 3-(4,5-dimers dimethylthiazol-2-yl)-2,5- diphenyltetrazolium bromide (MTT) were purchased from Sigma-Aldrich (Banglore, India). C6 glioma cells were procured from National Center for Cell Science (Pune, India). All other chemicals used in the experiment were of analytical grade.

\section{1. 1. Animals}

For PK studies, healthy Swiss albino mice of either sex (male: female ratio 1:1) were used. All animal related experiments were in accordance with CPSCEA guidelines. Animals were kept in polypropylene cages and maintained in the Jadavpur university animal house at normal room temperature $\left(20-25^{\circ} \mathrm{C}\right), 55 \%$ relative humidity environment with normal day and night cycle. Before experiments, animals were properly fed standard diet and drinking water ad libitum. The guidelines of Animal Ethical Committee, Jadavpur University were followed strictly during the entire study period. The animals were kept for three weeks in the animal house environment before study. A total number of 72 mice were used for plasma PK study, where as 56 animals were used for brain PK study. For hemolysis assay, total 30 animals were used. 


\section{2. Methods}

\section{2. 1. Method of Development of Experimental LNLs}

The experimental LNLs were prepared by conventional thin film hydration method with necessary modification of process parameters. ${ }^{24}$ For the formulation development, soya-L-a-lecithin (SL) was used as the main phospholipid. Along with that, we used DSPE and CHL. Briefly, weighed amount of LS, SL, CHL along with DSPE were dissolved in a required volume of chloroform taken in a $250 \mathrm{ml}$ round bottom flask. To this mixture, BHA ( $2 \% \mathrm{w} / \mathrm{v})$ was added as an antioxidant, since all phospholipids are generally sensitive to oxidation. The prepared mixture was then subjected to gentle rotation along with evaporation of the solvent in a rotary vacuum evaporator (Rotavap, PBU-6, Superfit, Mumbai, India), connected with a water bath. The temperature of the water bath was kept at $40{ }^{\circ} \mathrm{C}$. After, evaporation of chloroform, a thin film was formed along the inner wall of the round bottom flask. The flask was then kept in a dessicator overnight, which caused further removal of any residues of organic solvent still left in the thin film. On day 2, the formed thin film was hydrated with phosphate buffer saline (PBS), $\mathrm{pH} 7.4$ for about an hour at a rotation of $130 \mathrm{rpm}$. During this period, the formed film was completely dispersed in the PBS. Following hydration, the mixture was subjected to sonication in a bath-type sonicator (Trans-o-sonic, Mumbai, India). Sonication helps the reduction of large size vesicles into desired ultra small size range. After sonication, the formulation was allowed to stand for $1 \mathrm{~h}$ at room temperature followed by storage in a refrigerator overnight at $4{ }^{\circ} \mathrm{C}$. On next day (day 3 ), the sample was subjected to cold centrifugation at 15,000 rpm for 45 minutes (Sigma Lab Centrifuge, UK). After centrifugation, the supernatant was discarded and the sediments were collected, which was stored at -20 ${ }^{\circ} \mathrm{C}$ overnight. The pre-cooled samples were then lyophilized for $10 \mathrm{~h}$ (laboratory lyophilizer, Kolkata, India) to obtain dry powdered formulation and stored in a refrigerator $\left(4^{\circ} \mathrm{C}\right)$.

\section{2. 2. Development of Fluorescent LNLs}

For cellular uptake study, fluorescent LNLs were prepared with FITC. For this, FITC at a concentration $0.4 \% \mathrm{w} / \mathrm{v}$ was dissolved in a required volume of chloroform and ethanol mixture. From this stock preparation, about $50 \mu \mathrm{l}$ was used added during the first step of preparation of LNLs. All other steps mentioned above remained unchanged. ${ }^{25}$

\section{3. In vitro Studies of Experimental LNLs}

\section{3. 1. Determination of Average Vesicle}

Diameter (Z-average) and Surface Potential

For the determination of mean vesicle diameter (Z-average), polydispersity index (PDI) and surface charge (zeta potential) of the experimental formulations, a weighed amount of the formulation was dispersed in milli
Q water, sonicated for 5 minutes and observed under a dynamic light scattering (DLS) instrument (DLS-nano ZS, Zetasizer, Malvern Instrument Ltd, UK). ${ }^{23}$ The data was interpreted by instrument software.

\section{3. 2. Percentage of Drug Loading and Loading Efficiency}

For the calculation of amount of LS loaded in the experimental NLs, about $2 \mathrm{mg}$ of the lyophilized LNLs was dissolved in required volume of acetonitrile. The sample was then sonicated in a bath sonicator for $10 \mathrm{~min}$. After that, it was vortexed for another $3 \mathrm{~min}$ followed by centrifugation at 15,000 rpm. After centrifugation, the sediments were discarded and the absorbance of the collected supernatant was measured at $230 \mathrm{~nm}$ in UV-visible spectrophotometer (Advanced Microprocessor UV-Visible single beam, Intech 295, India). ${ }^{24,27}$

The amount of LS loaded in the experimental LNLs was calculated by applying following formula

\section{\% LS loading = Amount of LS in LNLs / Amount of LNLs obtained $\times 100$}

\% LS loading efficiency $=$ Practical \% LS loading / Theoretical \% LS loading

\section{3. 3. Yield Percentage}

To determine the $\%$ yield of each formulation batch, the fully dried LNLs obtained after lyophilization was weighed after each batch run. ${ }^{24}$ The $\%$ yield was calculated by applying following equation.

$\%$ Yield = Amount of LNLs obtained after lyophilization /

Total amount of all components used in the formulation batch $\times 100$

\section{3. 4. Surface Morphology Study by Field Emission Scanning Electron Microscopy (FESEM)}

To obtain surface morphology of the experimental formulation, electron microscope was used (JSM 6100, JEOL, Japan). For the experiment, lyophilized LNLs was spread on a carbon tape, fixed over a stub. Platinum coating was applied on the tested sample for 5 min with a voltage of $10 \mathrm{kV}$ by means of a platinum coater. ${ }^{22}$ Finally the samples were observed under FESEM under liquid nitrogen conditions. ${ }^{23}$

\section{3. 5. Cryo-Transmission Electron Microscopy (Cryo-TEM)}

For Cryo-TEM analysis, weighed amount of lyophilized LNLs was dispersed in milli-Q water. The disper- 
sion was vortexed in a cyclomixture for $5 \mathrm{~min}$ and a minute quantity of the dispersed LNLs $(4 \mu \mathrm{l})$ was taken on a clean grid. The sample was then immediately vitrified in liquid ethane followed by storage in liquid nitrogen condition until imaging. ${ }^{24,28}$ Images of the sample was taken with the help of a electron microscope (Tecnai Polora, version 4.6, Netherlands) equipped with an FEI Eagle $4 \mathrm{~K} \mathrm{x} 4 \mathrm{~K}$ charge-coupled device (CCD) camera. During imaging, vitreous grids were transferred into the electron microscope with the help of a cryostage. Throughout the experiment, the temperature of the samples was maintained $-170{ }^{\circ} \mathrm{C}$ to observe the LNLs in their native form without any damage to the internal structure.

\section{3. 6. In vitro Drug Release Study}

For the in vitro drug release study of the optimized LNLs, dialysis bag method was employed. ${ }^{24,28}$ The study was conducted at both $\mathrm{pH} 5$ and $\mathrm{pH}$ 7.4. For the experiment, a weighed amount of lyophilized sample was dispersed in PBS pH 7.4 containing sodium lauryl sulfate as a solubilizing agent (release medium). The dispersion was put inside a dialysis bag. The two ends of the dialysis bag were tied with the thread and the whole system was immersed in a beaker containing $100 \mathrm{ml}$ of the above release medium. After that, the beaker was placed on a magnetic stirrer at a rotation of $300 \mathrm{rpm}$ using a magnetic bead. At various time intervals for $24 \mathrm{~h}, 1 \mathrm{ml}$ of sample was withdrawn from the beaker with simultaneous replacement of the fresh release medium to maintain the sink condition. Similar procedure was followed for drug release study at $\mathrm{pH}$ 5. Each set was repeated in triplicate. The samples after collection were filtered with the help of membrane filter followed by measurement of the absorbance at $229 \mathrm{~nm}$ with the help of High performance liquid chromatography system.

\section{3. 7. Estimation of Drug Release Kinetics}

Release kinetics helps to predict the mechanism of drug release from the experimental LNLs. For this, the data obtained from the in vitro drug release studies were fitted in various kinetic models. We determined the release pattern of LNLs in five different models such as zero order (cumulative amount of drug released Vs time), first order (logarithmic value of cumulative amount of drug remained to be released Vs time), Higuchi (cumulative amount of drug released Vs square root of time), Korsmeyer-Peppas (logarithmic value of cumulative amount of drug released Vs logarithmic value of time), Hixson-Crowell (cube root of percentage drug remained to be released Vs time). ${ }^{26}$ The linearity of the plots was assessed from the calculated $\mathrm{R}^{2}$ values.

\section{3. 8. Assessment of in vitro Cytotoxicity}

The in vitro cytototxic effect of the LNLs was tested by MTT assay on C6 rat glioma cells and the effect was compared to that of free LS suspension at equivalent drug concentrations. ${ }^{29}$ For the experiment, the tested cell line was cultured in Dulbecco's modified eagle's medium containing $10 \%$ fetal bovine serum in a 96 well culture plate and maintained inside a $\mathrm{CO}_{2}$-incubator at $37^{\circ} \mathrm{C}$. After attaining required density of cells in the plates $\left(5 \times 10^{3}\right.$ cells per well), the cells were treated with varying concentrations of LNLs, free drug suspension along with blank NLs (without drug). As negative control, few of the wells were treated with equivalent volumes of pure culture medium. After $48 \mathrm{~h}$, media in each well was discarded and about 100 $\mathrm{ml}$ of MTT solution $(1 \mathrm{mg} / \mathrm{ml})$ was added to each well. The plate was kept inside $\mathrm{CO}_{2}$-incubator for another $4 \mathrm{~h}$. After incubation, MTT solution was removed out of the well followed by addition of dimethyl sulfoxide $(100 \mu \mathrm{l})$ in each well. Addition of dimethyl sulfoxide caused solubilization of formazan crystals to produce a purple color. The intensity of the color is related to the number of viable cells present after treatment in the well. The optical density was measured at $560 \mathrm{~nm}$ by micro plate reader (Spectra Max, Molecular Devices Corporation, Sunnyvale, USA). Percentage cell viability was evaluated by following formula

$\%$ cell viability $=$ Optical density of the sample at $560 \mathrm{~nm}$ of treated cells / Optical density of the sample at $560 \mathrm{~nm}$ of untreated cells $\times 100$

\section{3. 9. Assessment of Internalization Efficiency}

The internalization capacity of the selected fluorescent lipid nanostructures (FITC-LNLs) was tested on the C6 cells with the help of fluorescence microscopy. ${ }^{29,30}$ For the experiment, the cells were seeded in six-well culture plates and allowed to grow on cover slips at a density of $10^{4}$ cells per well. The volume of cell culture was taken as $3 \mathrm{ml}$ per well and incubated at $37^{\circ} \mathrm{C}$ in $\mathrm{CO}_{2}$-incubator for $24 \mathrm{~h}$. FITC-LNL was then added to the culture wells at two different subinhibitory concentrations of $50 \mathrm{ng} / \mathrm{ml}$ and 100 $\mathrm{ng} / \mathrm{ml}$. After $0.5 \mathrm{~h}$, cover slips were taken out and carefully washed with PBS. The treated cells were fixed with $4 \%$ paraformaldehyde solution. Following fixation, the cells were washed twice with fresh PBS and stained with DAPI. Cover slips were dried and mounted on glass slide for imaging by a fluorescence microscope (Carl Zeiss, Oberkochen, Germany).

\section{4. In vivo Studies}

\section{4. 1. Plasma and Brain Pharmacokinetic Studies}

Drug PK profile was studied both in plasma and brain tissue in healthy Swiss albino mice (body weight 20-25 g). For the PK study, animals were divided into three groups. ${ }^{22,30}$ Group I animals were intravenously administered LS suspension as per dose. Group II animals were intravenously (i.v.) administered LNLs, containing LS equivalent to $6.5 \mathrm{mg} / \mathrm{kg}$. Group III animals received sa- 
line (control group). At each time point of sample collection in Group I and II, 3 animals were taken for both plasma and brain PK studies, where as for Group III (control group) 2 animals were taken for each time point of the study.

For the plasma PK study, post i.v. dosing, blood samples were collected from each set of animals at $0.5,1,2,4$, $6,8,10,12$, and $20 \mathrm{~h}$ intervals by heart puncture in heparinized tubes. A total number of 54 mice (27 each for Group I and II) were used in test groups and 18 mice were used for control groups. The blood samples were centrifuged using cold centrifuge at $5000 \mathrm{rpm}$ for $10 \mathrm{~min}$. Plasma was collected and stored at $-40{ }^{\circ} \mathrm{C}$ till analysis.

For brain PK study, similar procedure as described above was followed. After i.v. injection, the animals were sacrificed at $0.5,1,2,4,8,12$ and $24 \mathrm{~h}$ intervals. Thus, a total number of 42 mice ( 21 each for Group I and II) were used in test groups where as 14 mice were used for the control group. Brains of each animal were removed. The whole brain was homogenized in a tissue homogenizer in PBS ( $\mathrm{pH}$ 7.4). The homogenates were stored at $-70{ }^{\circ} \mathrm{C}$ until further analysis.

For the determination of LS concentration in plasma samples, a Liquid chromatography with tandem mass spectrometry (LCMS/MS) technique was employed. The LCMS/MS Agilent $\mathrm{C}_{18}$ column was used. The mobile phase for the analysis was composed of acetonitrile, milli Q water along with formic acid $(0.1 \%)$. The flow rate of mobile phase was kept as $0.4 \mathrm{ml} / \mathrm{min}$. Sample volume for injection into chromatographic column was $20 \mu l$. The analyte was monitored using mass spectrometer equipped with a double quadruple along with electrospray ionization interface, operated in a positive mode (ESI+). To extract LS, samples were extracted with about three volume of methyl-tert-butyl ether. The mixture was then vortexed for 5 minutes followed by centrifugation at $3000 \mathrm{rpm}$ for $10 \mathrm{~min}$. After the process, the extracted LS present in the supernatant was collected. The organic solvent was allowed to dry under nitrogen atmosphere. For LCMS/MS analysis, the dried samples were then mixed in $100 \mathrm{ml}$ of mobile phase (acetonitrile: water: formic acid). From the prepared stock, about $50 \mathrm{ml}$ of reference standard solution was added in each sample. From the mixture, about $20 \mu \mathrm{l}$ sample was injected into the LCMS/MS column (Agilent 6410, Triple Quad MS-MS, USA). The important PK parameters i.e. area under the curve (AUC), area under the first moment curve (AUMC), volume of distribution (Vd), mean residence time (MRT), total body clearance (Clt) etc. were determined using non-compartmental PK Solver software (Version 2.0).

\section{4. 2. Hemolysis Study}

To check the biocompatibility and safety profile of the experimental lipid nanocarriers, hemolysis assay was carried out. For the study, blood samples were collected from Swiss albino mice. The samples were collected in pre-heparinized tubes, followed by cold centrifugation at $5000 \mathrm{rpm}$ for 5-7 min. After that, the red blood cells (RBCs) were washed with PBS (pH 7.4). In a 96 well plate, a measured amount of RBC suspension $(190 \mu \mathrm{l})$ was taken and treated with varying concentration of LNLs, free LS along with blank NLs (without drug). Double distilled water was used as the positive control. The samples were incubated for $1 \mathrm{~h}$ at $37^{\circ} \mathrm{C}$ followed by centrifugation for 5 $\mathrm{min}$ at $5000 \mathrm{rpm}$ to separate the un-lysed RBCs (as sediments). The supernatant was then taken and absorbance of the sample was measured at $570 \mathrm{~nm}$. Percentage hemolysis was calculated as per the previously reported method. $^{32}$

\section{5. Statistical Analysis}

All the experiments were carried out triplicate for accuracy and reproducibility. Data was expressed as the mean \pm standard deviation (SD). One-way ANOVA was used to evaluate statistical followed by Tukey post hoc test with the help of Origin Pro 8 soft ware. Differences were considered statistically significant when $\mathrm{p}<0.05$ at $95 \%$ confidence level.

\section{Results}

\section{1. In vitro Studies}

\section{1. 1. Formulation Optimization}

By varying concentration of drug and lipids along with specific manufacturing parameters, we prepared several formulations. All the formulations were characterized

Table 1. Formulation components, $\%$ yield, $\%$ drug loading and $\%$ drug loading efficiency of selected experimental formulations ${ }^{\mathrm{b}}$

\begin{tabular}{lccccc}
\hline $\begin{array}{l}\text { Formulation } \\
\text { code }\end{array}$ & $\begin{array}{c}\text { SL:CHL: } \\
\text { DSPE }\end{array}$ & $\begin{array}{c}\text { Drug:Lipid } \\
\text { ratio (w/w) }\end{array}$ & $\begin{array}{c}\text { \% yield } \\
\text { ratio (w/w) }\end{array}$ & $\begin{array}{c}\text { Practical \% } \\
\text { drug loading }^{\text {a }}\end{array}$ & $\begin{array}{c}\text { \% drug loading } \\
\text { efficiency }^{\mathbf{a}}\end{array}$ \\
\hline LNL-1 & $50: 50: 8$ & $1: 2$ & $58.3 \pm 2.2$ & $3.8 \pm 1.4$ & $57.8 \pm 2.9$ \\
LNL-2 & $225: 75: 8$ & $1: 5$ & $76.6 \pm 0.8$ & $8.8 \pm 1.5$ & $87.4 \pm 2.5$ \\
LNL-3 & $250: 50: 8$ & $1: 10$ & $63.5 \pm 1.4$ & $4.7 \pm 0.8$ & $69.3 \pm 1.4$ \\
\hline
\end{tabular}

a Data show mean $\pm \mathrm{SD}(\mathrm{n}=3)$. ${ }^{\mathrm{b}}$ Abbreviations: LNL, lomustine loaded lipid nanostructures; SL, soya-L- $\alpha$-lecithin; CHL, cholesterol; DSPE, 1,2-distearoyl-sn-glycero-3-phosphotidylethanolamine 
by different in vitro techniques. Out of several formulations, here we report three formulations having desired in vitro properties (Table 1 ). We basically compared the formulations based on their drug loading capacity, \% drug loading efficiency, as well as \% yield. Out of the three, based on these characteristics, we finally selected LNL-2 as the optimized one for further works.

\section{1. 2. Determination of \% Drug Loading, Loading Efficiency and Yield Percentage}

The $\%$ drug loading for LNL-2 was $8.8 \pm 1.5$, whereas for LNL- 1 and LNL-3, the values were $3.8 \pm 1.4$ and $4.7 \pm$ 0.8 respectively. LNL-2 also showed higher loading efficiency $(87.4 \pm 2.5)$ and yield percentage $(76.6 \pm 0.8)$ than other two formulations (Table 1). Based on these parameters, we selected LNL-2 for all other studies.

\section{1. 3. Determination of Average Vesicle Diameter (Z-average) and Surface Potential}

The diffraction light scattering (DLS) data revealed that the experimental formulations were below $100 \mathrm{~nm}$ size range. The optimized formulation (LNL-2) showed an average vesicle size of $83.41 \pm 1.3 \mathrm{~nm}$ (Table 2). The PDI

Table 2. Determination of Z-average, Poly dispersive index (PDI) and zeta potential of the selected formulation

\begin{tabular}{lccc}
\hline $\begin{array}{l}\text { Formulation } \\
\text { code }\end{array}$ & $\begin{array}{c}\text { Z-average } \\
(\mathbf{d n m})^{\mathbf{a}}\end{array}$ & PDI $^{\mathbf{a}}$ & $\begin{array}{c}\text { Zeta potential } \\
(\mathbf{m V})\end{array}$ \\
\hline LNL-2 & $83.41 \pm 1.3$ & $0.42 \pm 0.06$ & -56.7 \\
\hline
\end{tabular}

aData show mean \pm SD $(n=3)$

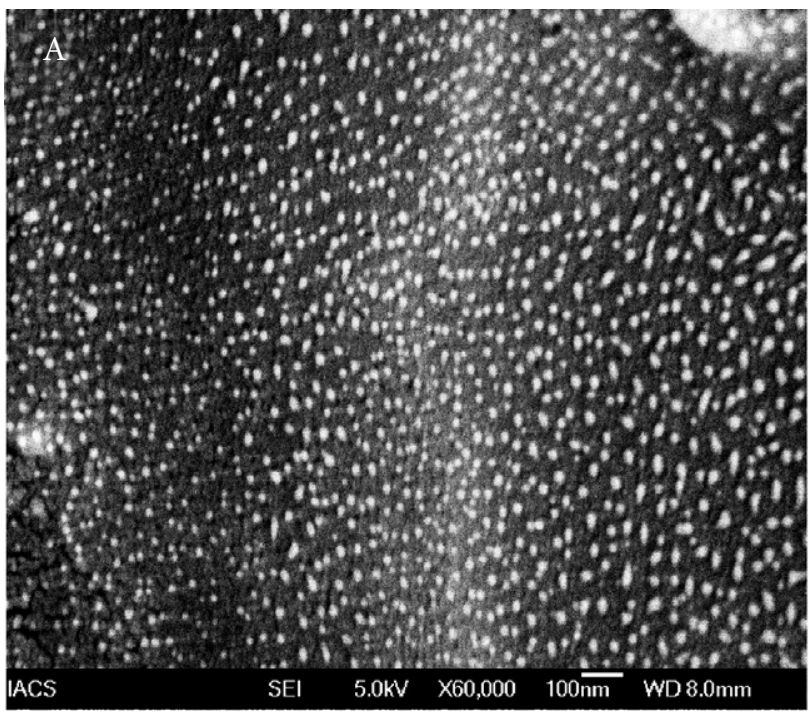

value of LNL-2 was $0.42 \pm 0.06$. Zeta potential of LNL-2 was found to be $-56.7 \mathrm{mV}$ (Table 2). The lower PDI value suggested a narrow size distribution pattern of the experimental formulation. Higher negative value of zeta potential was reported for the optimized formulation, which indicates the formulation would be stable in the suspension stage due to strong repulsive force between individual particles.

\section{1. 4. Surface Morphology Study by FESEM}

The FESEM image of the LNL-2 was reported here, which was taken at $60,000 \mathrm{x}$ magnification scale (Figure 1A). The FESEM data demonstrated the smooth surface morphology of LNL-2. All vesicles were found spherical in shape and within $30-50 \mathrm{~nm}$ size range. Though out the sample, there were no signs of any lumps or formation of big agglomerates, which justifies the good formulation characteristics.

\section{1. 5. Cryo-transmission Electron Microscopy (Cryo-TEM)}

Cryo-TEM analysis revealed the internal architecture of the formed vesicles. Image showed formation of unilamellar vesicles with intact lamellarity. Though, experimental NLs sample was found as polydisperse, i.e. both larger and smaller size vesicles were found, however all the vesicles were well below $50 \mathrm{~nm}$ as we desired. The larger size vesicle was around $40 \mathrm{~nm}$, where as smaller ones were around $25-30 \mathrm{~nm}$ as depicted in the photograph (Figure 1B). This was in good agreement with the data obtained from FESEM study. All the vesicles were found distinctively spread throughout the diluted sample without any damage to their native internal structure.

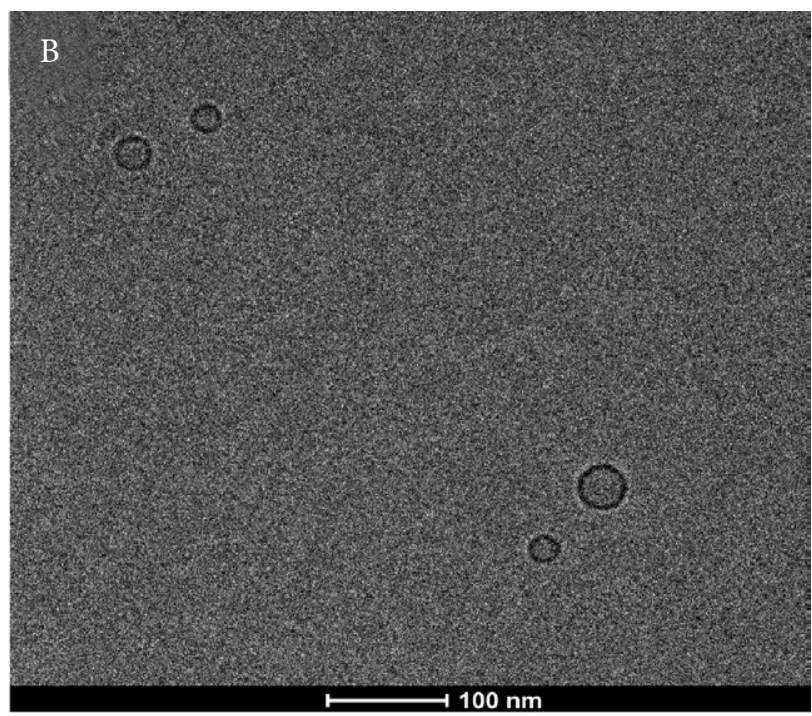

Fig. 1. (A) Field emission scanning electron microscopy (FESEM) image of optimized lomustine incorporated lipid nanostructures (LNL-2). (B) Cryo-transmission electron microscopy (Cryo-TEM) image of LNL-2 


\section{1. 6. In vitro Drug Release Study and Analysis of Drug Release Kinetics}

For the in vitro drug release study of the optimized formulation (LNL-2) at $\mathrm{pH} 5$ and $\mathrm{pH}$ 7.4, dialysis method was employed. Result showed a $\mathrm{pH}$ dependent sustained drug release pattern over $48 \mathrm{~h}$ experimental time period at pH 5 and 7.4 (Fig. 2). Initially, though the drug release increased with time, but after $10 \mathrm{~h}$, a more sustained release pattern was observed for the experimental formulation. However, amount of drug release was higher at pH 5 (endocytotic vesicular $\mathrm{pH}$ ). A cumulative amount of $82.34 \pm$ $2.71 \%$ LS was released from LNL-2 at pH 5 over the experimental study period. To determine the nature of drug release from the experimental formulation, release data was fitted in different kinetic equations. From the respective graphs, corresponding $\mathrm{R}^{2}$ values were calculated (Table 3 ). For LNL-2, among all the tested models, Koresmeyer-Peppas model demonstrated good linearity than other models $\left(\mathrm{R}^{2}=0.988\right)$.

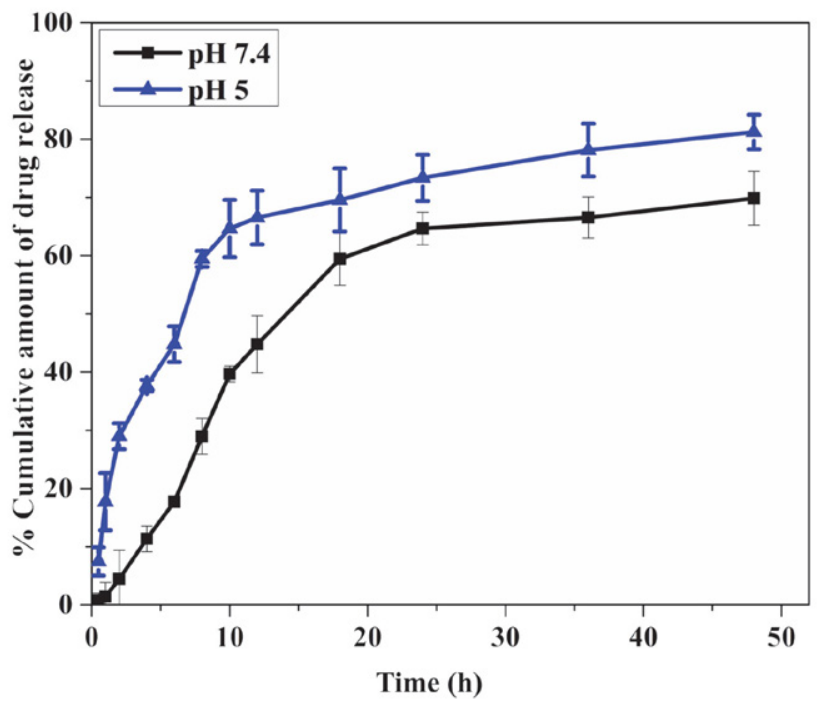

Fig. 2. In vitro drug release study of lomustine incorporated lipid nanostructures (LNL-2) at $\mathrm{pH} 7.4$ and $\mathrm{pH} 5$ respectively.

Table 3. In vitro drug release kinetics with $\mathrm{R}^{2}$ values of selected formulation

\begin{tabular}{ll}
\hline Kinetic Model & LNL-2 \\
\hline Zero Order Kinetics & $\mathrm{y}=2.430 \mathrm{x}+7.537$ \\
& $\mathrm{R}^{2}=0.786$ \\
First Order Kinetics & $\mathrm{y}=-0.014 \mathrm{x}+1.221$ \\
& $\mathrm{R}^{2}=0.923$ \\
Koresmeyer Peppas & $\mathrm{y}=0.915 \mathrm{x}+0.224$ \\
& $\mathrm{R}^{2}=0.977$ \\
Higuchi & $\mathrm{y}=19.68 \mathrm{x}-12.46$ \\
& $\mathrm{R}^{2}=0.944$ \\
Hixon Crowell Kinetics & $\mathrm{y}=-0.063 \mathrm{x}+2.532$ \\
& $\mathrm{R}^{2}=0.864$ \\
\hline
\end{tabular}

\section{1. 7. Assessment of in vitro Cytotoxicity}

In vitro cytotoxic or anti-proliferative effect of LNL-2 was evaluated in C6 rat glioma cells. MTT assay demonstrated a lower $\mathrm{IC}_{50}$ (inhibitory concentration causing 50\% of cell death) for LNL-2 as compared to free LS (Fig. 3). The plot of $\%$ cell viability against the tested dose $(\mu \mathrm{g} / \mathrm{ml})$ showed that with increase in concentration of both LNL-2 and free drug, the death rate of $\mathrm{C} 6$ cells increased. However, LNL-2 was found more effective $\left(\mathrm{IC}_{50} 9.4 \pm 0.8 \mu \mathrm{g} / \mathrm{ml}\right.$ ) as compared to free $\mathrm{LS}\left(\mathrm{IC}_{50} 23.8 \pm 1.3 \mu \mathrm{g} / \mathrm{ml}\right)$ at equivalent drug concentration. The results further showed that blank LNLs (without drug) were almost non-toxic to the experimental C6 cell line even at the highest tested concentration (Fig. 3). Percentage of viable cells treated with blank LNLs was much higher compared to free LS, LNL-2, justifying non-toxic nature of ingredients used for the formulation.

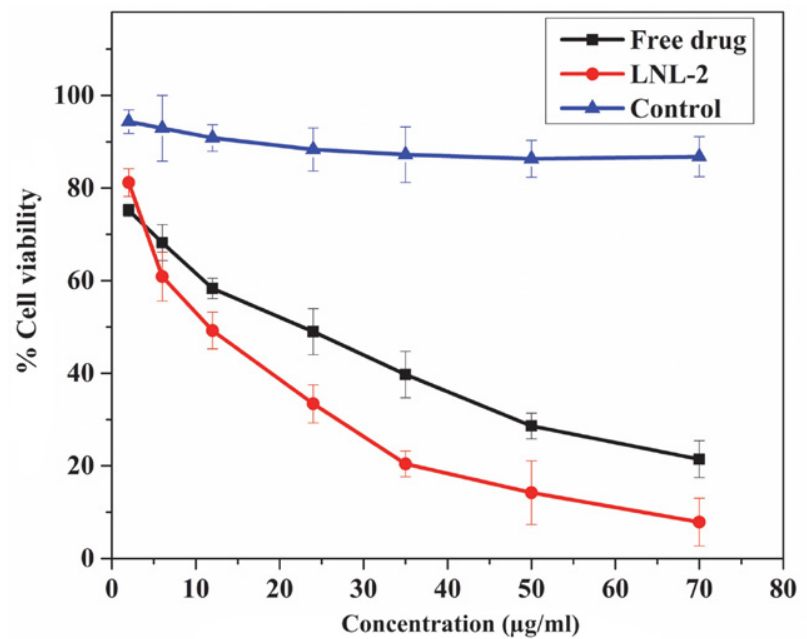

Fig. 3. Comparison of percentage C6 cell viability upon treatment with optimized lomustine loaded lipid nanostructures (LNL-2), free drug, and blank lipid nanostructures (LNLs).

\section{1. 8. Assessment of internalization Efficiency}

To estimate whether the optimized formulation possesses the ability to permeate into the cancer cells or not, we tested in vitro internalization capacity of the fluorescent optimized formulation (FITC-LNL-2) at two different subinhibitory concentrations in $\mathrm{C} 6$ cells by fluorescence microscopy (Fig. 4). Fluorescent images of the cell line clearly showed preferential internalization of FITC-LNL-2 into the cells. The fluorescent formulation could successfully penetrate into cell and distributed throughout the cytoplasm. However, no nuclear permeation by the formulation was visualized. The nuclei of the cells were stained by DAPI, which distinctively visualized in the image and thus confirmed that FITC-LNL-2 could not cross the nucleus. A higher amount of internalization was observed in C6 cells at $100 \mathrm{ng} / \mathrm{ml}$ than the cells treated with $50 \mathrm{ng} / \mathrm{ml}$ during $0.5 \mathrm{~h}$ study period. Thus, a concentration dependent uptake was clearly noticed for the experimental formulation. 

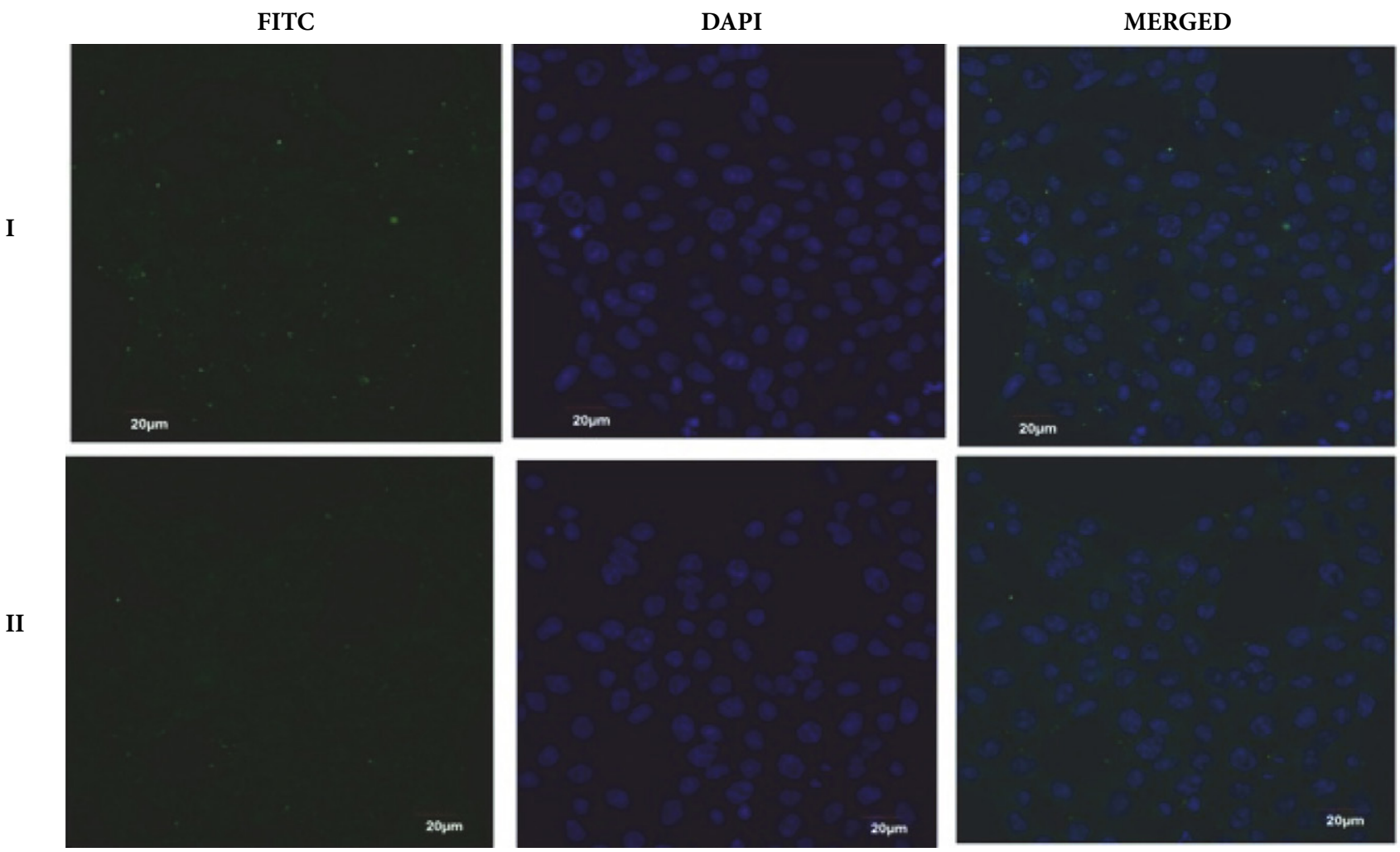

Fig. 4. Cellular internalization study of fluorescein isothiocyanate labelled lomustine loaded lipid nanostructures (FITC-LNL-2) in C6 rat glioma cells $(0.5 \mathrm{~h}$ incubation) by confocal laser scanning microscopy at I) $50 \mathrm{ng} / \mathrm{ml}$; II) $100 \mathrm{ng} / \mathrm{ml}$. The nucleus was stained with 4',6-diamidino-2-phenylindole (DAPI).

\section{2. In vivo Studies}

\section{2. 1. Plasma Pharmacokinetics Study}

PK study was carried out to detect LS at different time points in blood of the experimental mice. From plasma PK study, a reasonable difference was observed in the important PK parameters between LNL-2 and free LS treatments (Table 4). From the graph between plasma drug concentration Vs time, a prolonged blood residence time for LNL-2 was clearly observed than free LS (Fig. 5A). After $8 \mathrm{~h}$, the concentration of LS from conventional suspension was not detectable; but LS encapsulated in LNLs showed a much sustained release of the drug and even detectable at $20 \mathrm{~h}$ $(21.33 \mathrm{ng} / \mathrm{ml} \pm 1.41)$. However, at $24 \mathrm{~h}$, the LS concentration dropped beyond threshold identification limit of LCMS/ $\mathrm{MS}$, and thus was non-identifiable. $\mathrm{AUC}_{0-\infty}$ value was $7214.32 \pm 311.41 \mathrm{ng} \mathrm{h} \mathrm{ml}^{-1}$ for free LS administration, whereas it was $12451.1 \pm 234.16 \mathrm{ng} \mathrm{h} \mathrm{ml}^{-1}$ for LNL-2 administration. Similarly other important parameters like AUMC, MRT also showed preferential enhancements for LNL-2 as compared to free LS injection. MRT was increased almost three fold for LNL-2 treated animals $(9.31 \mathrm{~h})$ than the animals treated with free LS $(3.64 \mathrm{~h})$.

\section{2. 2. Brain Pharmacokinetics Study}

Brain PK data showed increased brain availability of LS from LNL-2 than LS suspension (Fig. 5B). The $\mathrm{AUC}_{0-\infty}$

Table 4. Estimation of plasma and brain pharmacokinetic parameters of lomustine (LS) after intravenous bolus administration of free lomustine (LS) and lomustine loaded lipid nanostructures (LNL-2) suspensions

\begin{tabular}{|c|c|c|c|c|}
\hline \multirow[b]{2}{*}{ Pharmacokinetic parameters } & \multicolumn{2}{|c|}{ Plasma $^{\mathrm{a}}$} & \multicolumn{2}{|c|}{ Brain $^{a}$} \\
\hline & free LS & LNL-2 & free LS & LNL-2 \\
\hline $\operatorname{AUC}_{0-\infty}\left(\mathbf{n g ~ h ~ m l ^ { - 1 }}\right)$ & $7214.32 \pm 311.41$ & $12451.1 \pm 234.16^{*}$ & $3302.635 \pm 138.6$ & $15113.77 \pm 221.4^{*}$ \\
\hline $\operatorname{AUMC}_{0-\infty}\left(\mathrm{ng} \mathrm{h}^{2} \mathrm{ml}^{-1}\right)$ & $31541.11 \pm 1541.15$ & $91322.42 \pm 6561.25^{*}$ & $41505 \pm 231.66$ & $87657 \pm 172.62^{*}$ \\
\hline $\mathrm{Cl}\left(\mathrm{L} \mathrm{h}^{-1}\right)$ & $0.072 \pm 0.04$ & $0.211 \pm 0.31$ & $0.013 \pm 0.06$ & $0.531 \pm 0.32^{*}$ \\
\hline $\operatorname{MRT}_{0-\infty}(\mathbf{h})$ & $3.64 \pm 0.32$ & $9.31 \pm 0.22^{\star}$ & $5.61 \pm 1.21$ & $12.49 \pm 3.21^{\star}$ \\
\hline $\mathrm{V}_{\mathrm{ss}}(\mathrm{ml})$ & $0.039 \pm 2.31$ & $0.151 \pm 0.13$ & $2.431 \pm 0.03$ & $4.311 \pm 1.76^{*}$ \\
\hline
\end{tabular}

${ }^{a}$ Data show mean $\pm S D(n=6)$. AUC: area under the plasma concentration time curve; AUMC: area under the first moment curve; Cl: clearance; MRT: mean residence time; $t_{1 / 2}$, plasma half life; $V_{\text {ss }}$ s steady state volume of distribution ${ }^{*}$ Data were significantly different $(p<0.05)$ where free LS and LNL-2 were compared. It was assessed by one-way analysis of variance (ANOVA) through Tukey-Kramer's multiple comparisons test. 
value of LS from selected formulation (LNL-2) (15113.77 $\pm 221.4 \mathrm{ng} \mathrm{h} \mathrm{ml}^{-1}$ ) was significantly higher than that from LS suspension (3302.635 $\left.\pm 138.6 \mathrm{ng} \mathrm{h} \mathrm{ml}^{-1}\right)$. A significant difference was also found in $\mathrm{AUMC}_{0-\infty}$ values in between LNL-2 and LS suspension treated groups (87657 \pm 172.62 Vs $41505 \pm 231.66)$. Data showed a higher volume of distribution and a lower rate of clearance $(\mathrm{Cl})$ of drug from LNL-2 than that from LS suspension (Table 4). A 2.5 fold enhancement in the mean residence time of the drug in LNL-2 treated group was reported as compared to free LS treated group. Higher value of AUC, MRT, $V_{\text {ss }}$ along with lower value of $\mathrm{Cl}$ signifies higher bioavailability and prolonged retention of drug from LNL-2 in the brain tissue. Brain PK data further provided quantitative assessment of the superiority of the experimental formulation in crossing BBB than conventional free LS.

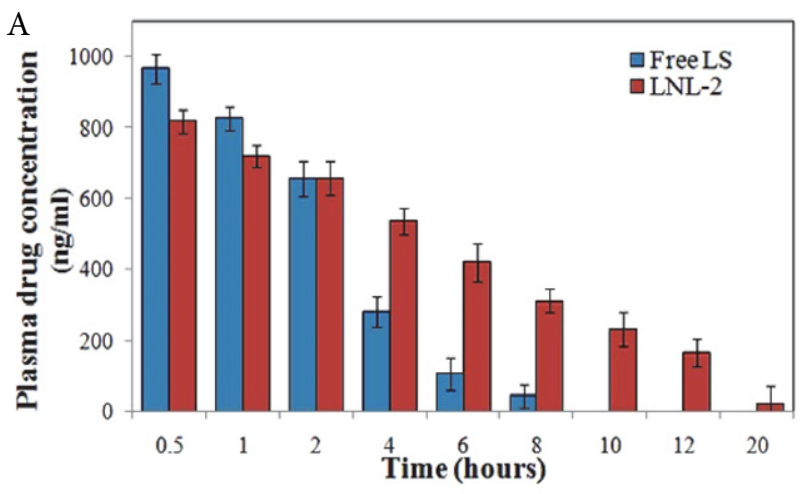

$\mathrm{B}$

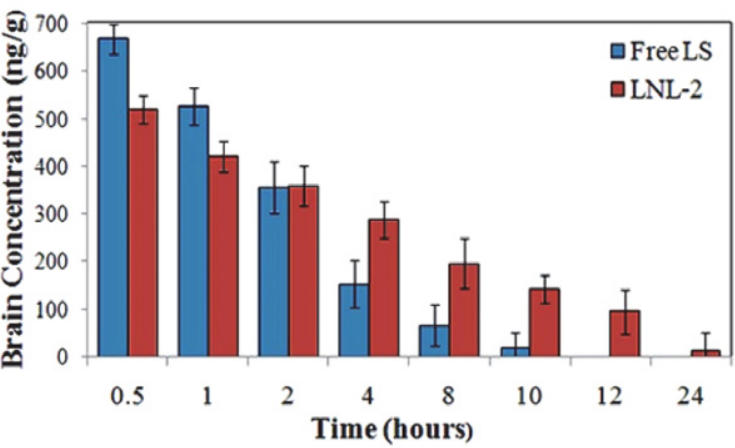

Fig. 5. A) Plasma concentration-time profiles of lomustine (LS) in Swiss albino mice after $i . v$. administration of lomustine loaded lipid nanostructures (LNL-2) and free lomustine (LS) suspension. ${ }^{a}$ Data show mean $\pm S D(n=6)$; B) Brain concentration-time profiles of LS in Swiss albino mice after i.v. administration of LNL-2 and free LS suspension. ${ }^{a}$ Data show mean $\pm \mathrm{SD}$.

\section{2. 3. Hemolysis Study}

Hemolytic assay was carried out in mice RBCs in order to estimate the blood-compatibility of the optimized formulation (LNL-2) and drug-free NLs along with free drug at different concentrations $(0.25-50 \mu \mathrm{g} / \mathrm{ml})$. As depicted in Fig. 6, RBCs up on treatment with LNL-2 showed negligible toxicity (hemolysis up to $\sim 7.1 \%$ ) even at highest tested drug concentration. A comparatively lower toxic ef-

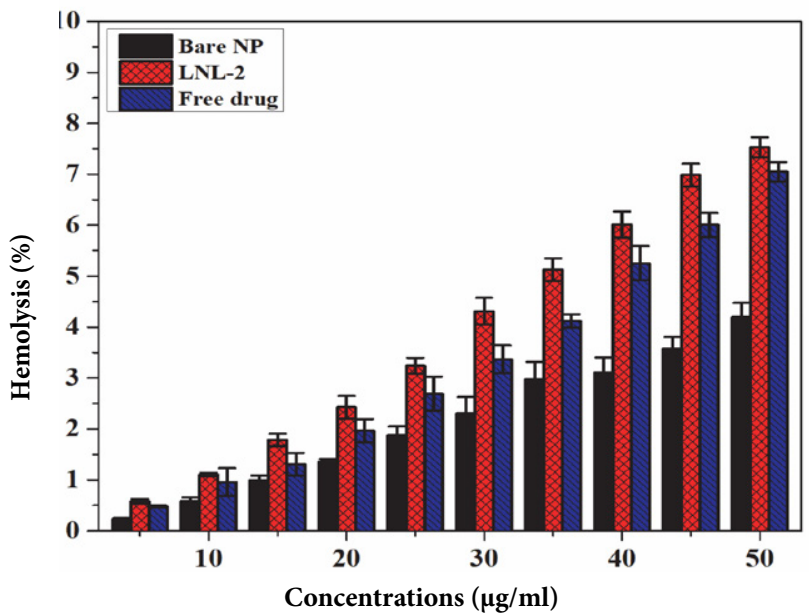

Fig. 6. Comparison of the hemolysis percentage of mice red blood red blood cells (RBCs) treated with lomustine loaded lipid nanostructures (LNL-2), free lomustine (LS) and bare nanocarriers. Data shown for mean $\pm \operatorname{SD}(n=3)$.

fect on RBCs was observed for the free drug, where as the drug-free NLs were also found almost non toxic at all tested concentrations. The haemolytic values were observed up to $7.1 \%$ for LNL-2, where as $4.2 \%$ for blank NLs. For free LS, up to $6.8 \%$ haemolytic effect was detected. Over all, the haemolytic effect follows the order as blank NLs < free LS < LNL-2. Lower haemolytic activity of the tested formulation suggested its safety and compatibility nature for in vivo applications.

\section{Discussion}

The present study was intended to develop an optimized method for formulation of LS loaded NLs and to evaluate its potentiality in glioma cells. LS is a FDA approved established anticancer drug used for the treatment of different types of cancers including glioma. However it is associated with severe side effects like bone marrow depression along with shorter plasma half life. Thus, it is hypothesized that phospholipid based nanostructures may improve the delivery of LS to glioma cells and maintain desired therapeutic concentration in brain tissue over a period of time due to sustained drug release. Further, it would reduce the dose related severe toxicity of the conventional dosage forms. During product development, we found that specific formulation composition and critical in-process parameters have significant impact on the formation of nanosize LNLs and to produce desired in vitro properties. Initially we varied amount of SL, CHL (at a fixed LS concentration) to develop different batches of formulations and tested in vitro drug loading, loading efficiency, yield percentage etc. in each batch. However, amount of DSPE was kept constant. DSPE is the type of sphingo lipid, which is present abundantly in brain tissue. Thus, brain tissue-mimicking nature of DSPE is expected 
to increase the accumulation and retention the experimental formulation in brain tissue. Reports from our previous work also ustified this hypothesis. ${ }^{24}$

In the present work, percentage drug loading was initially increased with increase in the amount of drug. However, beyond certain amounts, percentage loading was not increased in direct proportion with the amount of drug. That indicates \% drug loading was independent on amount of drug in the formulation. Thus, higher amount of drug does not guarantee higher drug loading in NLs. This was also in good agreement with the previous reports. ${ }^{24,28}$ Further, different process parameters, such as duration of hydration, temperature, sonication time, speed and time of centrifugation etc. affected the morphology, average vesicle size as well as drug loading capacity of the formulations. In our work, we have therefore standardized critical in-process parameters to obtain LNLs with desired physicochemical properties. At a fixed ratio of 1:5 drug:lipid (w/w) along with specific manufacturing parameters such as $45 \mathrm{~min}$ hydration in PBS at $140 \mathrm{rpm}, 40 \mathrm{~min}$ sonication in a bath type sonicator, $45 \mathrm{~min}$ ultra centrifugation at $15,000 \mathrm{rpm}$ etc. the obtained formulation showed satisfactory characteristics in terms of \% yield, \% drug loading and loading efficiency and thus taken for further studies throughout the work.

The selected formulation (LNL-2) showed a satisfactory percentage of drug loading. For nanosize vesicular carriers, it has always been a problem to achieve higher drug loading. However, in our case, a reasonable drug loading of $8.8 \%$ was reported, which may be attributed to the standardized formulation composition and in-process parameters selected in our study.

The experimental lipid nanostructures (LNL-2) had a nanosize range as depicted from DLS study with a narrow distribution pattern. A lower PDI value of LNL-2 $(0.42 \pm 0.06)$ signifies homogenous distribution pattern of nanostructures in the formulation. It is known that smaller size nanodrug carriers remain suspended for a longer period of time as compared to larger size carriers, since the rate of sedimentation of suspended particles is mostly governed by stoke's law. According to stoke's law, rate of sedimentation of suspended particles are directly proportional to the diameter of the suspended particles. Again, a higher value of zeta potential on the experimental formulations $(-56.7 \mathrm{mV})$ would help them to remain separated from each other due to higher repulsive force between individual vesicles. It has been reported that a zeta potential of more negative than $-30 \mathrm{mV}$ or more positive than $+30 \mathrm{mV}$ is taken as critical to form stable suspensions. ${ }^{24,27}$ Thus, in our case, ultra micron size (below $100 \mathrm{~nm}$ ) and higher negative surface charge of selected formulation would help to form stable suspension.

FESEM images demonstrated smooth surface morphology, nanosize range $(30-40 \mathrm{~nm})$ and a clear homogenous nature of the experimental lipid nanostructues. It was observed that size of lyophilized LNL-2 found in the FE-
SEM image was less than those detected by DLS method. It is because the DLS method mostly measures average hydrodynamic diameter of the vesicles in aqueous phase, whereas in FESEM dried powdered samples (lyophilized) are analysed. The formed vesicles while dispersed for a reasonable time period in milli $\mathrm{Q}$ water during sample preparation for DLS measurement might swell and increase in size than their native form. We found similar observations in some of the previous reports also. ${ }^{24,25,31}$ However, size of the sample observed by cryo-TEM was in good agreement with that of FESEM. Cryo-TEM method actually maintains the LNLs in their native form where they are observed under liquid nitrogen environment. Thus, the delicate nature of lipid vesicles is well maintained in cryo-TEM method than normal TEM. In our study, cryo-TEM images showed intact bilayer of the formed vesicles without any damage to their native structure. We have taken experimental LNLs at a diluted state so that the vesicles could be distinctively visualized. Cryo-TEM thus confirmed satisfactory production of LNLs by the standardized process as well as maintenance of their internal architecture.

In vitro drug release study was carried out at physiological pH of blood (i.e. $\mathrm{pH}$ 7.4) as well as endocytotic vesicular $\mathrm{pH}(\mathrm{pH} \mathrm{5)}$ to simulate different in vivo environments. Drug release though found to be sustained nature for both the $\mathrm{pH}$, however, a higher cumulative percentage of drug was released at $\mathrm{pH} 5$, than at $\mathrm{pH}$ 7.4. For both cases, initially, the amount of drug release was increased with time, but after $10 \mathrm{~h}$, a more sustained release pattern was observed. A comparatively lower cumulative drug release at $\mathrm{pH} 7.4$ signifies reduced loss of the drug at physiological condition and more specific to targeted site. As tumor microenvironment has reduced $\mathrm{pH}(\mathrm{pH}$ 5-5.5) due to anaerobic respiration of malignant cells, higher drug release from the optimized formulation at $\mathrm{pH} 5$ would enhance its therapeutic action at tumor area. Further, the sustained release behavior of the formulation would reduce dose, dosing frequency as well as associated toxic effects of LS. The pattern of drug release when fitted to different kinetics models, the formulation was best fitted with the Korsmeyer-Peppas kinetics model. Adherent to this model signifies that the drug release pattern from LNL-2 might follow complex mechanisms and include both diffusion and erosion. In case of the Korsmeyer-Peppas model, the fraction of drug release with time is generally represented as $M_{t} /$ $\mathrm{M}_{\infty}=\mathrm{Kt}^{\mathrm{n}}$, where the release mechanism is governed by ' $\mathrm{n}$ '. The drug release is said to follow Fickian diffusion mechanism, when $\mathrm{n} \leq 0.45$. Similarly, when value of ' $\mathrm{n}$ ' lies in between $0.45-0.89$, the drug release is said to follow non-Fickian diffusion mechanism and when $\mathrm{n}$ remains $\geq$ 0.89 , it is considered Case II (relaxational) transport. ${ }^{28} \mathrm{In}$ our case, ' $n$ ' value was found as 0.724 , which suggests that the drug release from LNL-2 might follow non-Fickian diffusion mechanism.

The in vitro cytotoxicity data demonstrated higher death rate of C6 cells treated with LNL-2 as compared to 
free LS suspension at equivalent drug concentration. Data clearly revealed better antitumor efficacy of the tested formulation than free drug. LS delivered through LNLs was more cytotoxic to the glioma cells with lower $\mathrm{IC}_{50}$ value $(9.4 \mu \mathrm{g} / \mathrm{ml})$ as compared to free LS $(23.8 \mu \mathrm{g} / \mathrm{ml})$. The blank formulation (without drug) showed no significant impact on the cell death rate even at highest tested concentrations. Clearly, it suggests the biocompatible and non-toxic nature of excipients used in the formulation development, which is a good sign for in vivo applications.

In order to visualize the internalization of LNL-2 by C6 cells, FITC was used as a fluorescent marker. The FITCLNL-2 produced green fluorescence while visualized under fluorescence microscope. Further, DAPI was used as coloring agent to stain nucleus, which produces blue fluorescence. In the study, we have chosen two different concentrations of the LNL-2, which are subinhibitory concentrations, i.e. quite less than the reported $\mathrm{IC}_{50}$ value. Thus, at these concentrations, no damage to the normal cellular architecture could be there and the cells were visualized in their native form. Confocal images depicted a preferential uptake of FITC-LNL-2 by C6 cells. The formulation was predominantly spread throughout the cytoplasm, around the nucleus. Higher cellular internalization of the optimized formulation could be attributed to the ultra micron size range. It may be possible that due to much smaller size as well as higher lipophilic property, the experimental LNLs could sufficiently permeate through the cancer cells, which is again a good finding towards successful application of the experimental formulation for the treatment of glioma.

The PK parameters of LNL-2 treated mice demonstrated a higher value of AUC, AUMC, $V_{\text {ss }}$, and MRT in comparison to animals treated with free LS suspension. The plasma drug concentration for LNL-2 treated group at $24 \mathrm{~h}$ was reasonably higher than that of LS treated groups. The drug concentration for free LS treated groups was not detectable after $10 \mathrm{~h}$, since it dropped beyond the minimum detectable limit $(10 \mathrm{ng} / \mathrm{ml})$ of our LCMS/MS system, whereas LS from LNL-2 showed its presence up to $20 \mathrm{~h}$ study period. The data justified the potential of the optimized formulation to remain circulated for prolonged period of time in blood. Further, due to longer blood residence profile, the formulation would get sufficient time to reach into brain tissue by crossing $\mathrm{BBB}$. Owing to its extreme small size, and higher negative surface charge, the experimental LNLs might escape from the trap of reticuloendothelial cells successfully and could maintain a longer presence in blood.

A similar observation was found in case of brain PK parameters in mice treated with LNLV-2/free LS. The LS incorporated in lipid nanostructures showed a much sustained release up to $24 \mathrm{~h}$ than LS suspension. Initially, LS concentration was higher in case of plain suspension than LNL-2. Interestingly, at $2 \mathrm{~h}$ post i.v. injection, drug concentration was almost similar for both LNL-2 and free LS suspension. However, after $4 \mathrm{~h}$, drug level was drastically reduced in case of free LS, whereas it dropped in a much controlled manner for LSNL-2 till $24 \mathrm{~h}$ of study period. After 10h, the drug level from free LS reduced beyond the threshold limit of detection of LCMS/MS and thus could not be detected. Even at $24 \mathrm{~h}, 13.76 \mathrm{ng} / \mathrm{ml}$ of drug was detected from LNL-2, which signifies the sustained release and prolonged residence time of LNL-2 in brain tissue. The significant enhancements in AUC and AUMC in the LNL-2 treated group signified higher bioavailability of the drug from LNL-2 than free LS. Brain PK results further confirmed the potentiality of optimized lipid nanostructures to cross $\mathrm{BBB}$ and enter into brain for a reasonable time period, which is very crucial data for successful in vivo applications in glioma.

Though application of LS for the treatment of brain and intracranical tumors are not new, but development of novel strategies to enhance its efficacy and to reduce the associated toxic effects have been tried in recent times only. Funmilola A. F. et al., 2016 reported the development of LS loaded nanoparticles for improved brain delivery and to check the dose-related myelosuppression. The in vivo efficacy of the selected LS loaded nanoparticles was assessed in orthotopic U87 MG glioblastoma animal model. Results showed that LS delivered through nanoparticulate system improved the survival of intracranial tumour bearing mice and also did not produce no additional myelosuppressive effects. ${ }^{21}$ Another work reported by Salman J. et al showed efficacy of LS loaded superparamagnetic iron oxide nanoparticles on U87 MG cancer cell line. ${ }^{33}$ The encapsulation efficiency for the LS loaded nanoformulation was $46 \pm 6.8 \%$. The experimental nanostructures were found cytotoxic on U87 MG cancer cells at concentration above $100 \mu \mathrm{g} / \mathrm{mL}$. Further, they did not report PK studies or any other related animal experiments to justify the suitability of the experimental nanoparticle formulations for in vivo applications.

We must say that the present work will be quite different from all such reported works, since till now LS loaded LNLs have not been evaluated for their in vitro efficacy on C6 glioma cells. Further, no study has been reported so far both the plasma and brain PK profile of LS encapsulated in LNLs. Hemolysis assay further adds novelty to the work. The simple formulation technique used for the study along with clear optimization of critical manufacturing parameters would be beneficial for furthering its research towards technology transfer. Higher encapsulation efficiency of the optimized formulation adds value to the work. Overall the data presented in FESEM, cryo-TEM, confocal microscopy, PK profile etc. stands unique in their parts.

For the desired in vivo applications, blood compatibility of the nanodrug formulations is an essential criterion. Hemolysis assay of the selected formulation in the experimental mice RBCs depicted an excellent blood compatibility nature of LNL-2 since a very low hemolysis (up to $7.1 \%$ ) was observed for the optimized formulation even 
at highest tested concentration. The haemolytic effect for the free LS was also less than LNL-2. From the negligible hemolysis activity, it may be concluded that LNL-2 could be employed as a safe, non-toxic and effective nanocarrier platform for its future clinical investigations.

\section{Conclusion}

The study reported an optimized and easily controllable method for the development of lipid based nanostructures for sustained delivery of LS for the treatment of glioma. The selected formulation (LNL-2) showed a preferable nanosize (within $50 \mathrm{~nm}$ ) as depicted from FESEM and cryo-TEM study. A reasonable drug loading (8.8\%) was reported for LNL-2 along with a sustained in vitro drug release profile during a $48 \mathrm{~h}$ study period. Owing to its ultra small size and high lipophilic nature, LNL-2 showed preferential internalization in C6 glioma cells. MTT assay showed a higher toxicity of LNL-2 on the tested cancer cells than free LS. The formulation showed improved PK profile both in blood and brain in experimental mice models than free drug suspension. A higher mean residence time of LNL-2 in blood signifies its higher in vivo stability. Significant increase in important brain PK parameters like AUC and MRT for LNL-2 justified its higher bioavailability and prolonged retention in brain tissue. Further negligible hemolysis in mice RBCs justified the non-toxic and biocompatible nature of LNL-2 for safe in vivo application. The formulation development steps were simple and well standardized, which would be helpful during technology transfer. Results of the study overall suggest the potential application of LNL-2 for sustained delivery of LS for glioma treatment. However, further in vivo testing on various pharmacological and toxicological aspects of LNL-2 is warranted for its future clinical application.

\section{Declaration of interest}

The authors of this article have no conflict of interest to declare.

\section{Acknowledgement}

The authors are very much grateful to Prof. Manoj Ranjan Nayak, President, Siksha 'O' Anusandhan (Deemed to be University) for providing necessary research facilities and encouragement.

\section{Data Availability Statement}

The authors hereby state that all data available in the article can be shared for scientific search as there are no ethical issues. Neither, these data violate the protection of human subjects, nor any other valid ethical, privacy, or security concerns.

\section{References}

1. D. Giakoumettis, A. Kritis, and N. Foroglou, Hippokratia. 2018, 22, 105-112.

2. S. Kesari, in Seminars in Oncology. 2011,38, 2-10. DOI:10.1053/j.seminoncol.2011.09.005

3. D. N. Louis, Acta Neuropathol, 2016, 3, 803-820. DOI:10.1007/s00401-016-1545-1

4. S. Stamatovic, R. Keep, and A. Andjelkovic, Curr. Neuropharmacol. 2018, 6, 179-192. DOI:10.2174/157015908785777210

5. J. Guo et al., Biomaterials. 2011, 26, 8010-8020. DOI:10.1016/j.biomaterials.2011.07.004

6. A. Bhowmik, R. Khan, and M. K. Ghosh, BioMed Research International, 2015, 2015, 1-20. DOI:10.1155/2015/320941

7. K. K. Jain, Nanomedicine. 2012, 7, 1225-1233. DOI: $10.2217 / \mathrm{nnm} .12 .86$

8. H. Athmakur and A. K. Kondapi, Int. J. Appl. Pharm. 2018, 10, 234-241. DOI:10.22159/ijap.2018v10i6.28004

9. M. C. Chamberlain, Expert Review of Neurotherapeutics, 2010, 10, 1537-1544. DOI:10.1586/ern.10.32

10. Y. Hao, L.Wang, Y.Zhao, D. Merg, D.Li, H.Li, B.Zhang, Macromol. Biosci. 2015, 15, 1571-1585.

DOI:10.1002/mabi.201500091

11. X. Li et al., Journal of Drug Targeting, 2017, 25, 17-28. DOI:10.1080/1061186X.2016.1184272

12. X. Hu, F. Yang, Y. Liao, L. Li, and L. Zhang, Drug Deliv. 2017, 24, 121-132. DOI:10.1080/10717544.2016.1233590

13. M. L. Bondì, R. Di Gesù, and E. F. Craparo, Methods in Enzymology. 2012, 508. 229-251.

DOI:10.1016/B978-0-12-391860-4.00012-4

14. A. Laouini, C. Jaafar-Maalej, I. Limayem-Blouza, S. Sfar, C. Charcosset, and H. Fessi, J. Colloid Sci. Biotechnol, 2012, 1, 147-168. DOI:10.1166/jcsb.2012.1020

15. A. Akbarzadeh et al., Nanoscale Res. Lett, 2013, 8, 102-110. DOI:10.1186/1556-276X-8-102

16. N. M. Shamhari, B. S. Wee, S. F. Chin, and K. Y. Kok, Acta Chim. Slov. 2018, 65, 578-585. DOI:10.17344/acsi.2018.4213

17. Sonali, Rahul.S, Nitesh.S, Gunjan.S, Biplob,S, Drug Deliv. 2016, 23, 1261-1271. DOI:10.3109/10717544.2016.1162878

18. S. Yi, F. Yang, C. Jie, and G. Zhang, Artif. Cells, Nanomedicine Biotechnol. 2019, 47, 3438-3447. DOI:10.1080/21691401.2019.1652628

19. K. A. Harvey, Zhidong. X, Haiyan.W, Karen. P, J. Neurosurg. 2015, 122, 547-556. DOI:10.3171/2014.10.JNS14759

20. S. Lonardi, A. Tosoni, and A. A. Brandes, Cancer Treat. Rev. 2005, 31, 79-89. DOI:10.1016/j.ctrv.2004.12.005

21. F. A. Fisusi et al, Pharm. Res. 2016, 33, 1289-1303. DOI:10.1007/s11095-016-1872-x

22. A. Mehrotra and J. K. Pandit, J. Nanomed. Nanotechnol. 2015, 6, 328-341. DOI:10.4172/2157-7439.1000328

23. O. Arjmand, M. Ardjmand, A. M. Amani, and M. H. Eikani, Acta Chim. Slov. 2020, 67, 496-506.

DOI:10.17344/acsi.2019.5513

24. B. S. Satapathy, B. Mukherjee, R. Baishya, M. C. Debnath, N. S. Dey, and R. Maji, RSC Adv. 2016, 6, 85261-85274. DOI:10.1039/C6RA16426A 
25. B. Sinha, B. Mukherjee, and G. Pattnaik, Nanomedicine Nanotechnology, Biol. Med. 2013, 9, 94-104.

DOI:10.1016/j.nano.2012.04.005

26. N. Shekhar Dey, B. Mukherjee, R. Maji, and B. Sankar Satapathy, Curr. Cancer Drug Targets. 2015, 16, 357-372. DOI:10.2174/1568009616666151106120606

27. A. Rudra, R. M. Deepa, M. K. Ghosh, S. Ghosh, and B. Mukherjee, Int. J. Nanomedicine. 2010, 5, 811-823.

DOI:10.2147/IJN.S13031

28. T. K. Shaw et al., Drug Deliv. 2017, 24, 346-357. DOI:10.1080/10717544.2016.1253798

29. R. Maji, N. S. Dey, B. S. Satapathy, B. Mukherjee, and S. Mondal, Int. J. Nanomedicine. 2015, 9, 3107-3118.

DOI:10.2147/IJN.S63535
30. J. Panda, B. S. Satapathy, S. Majumder, R. Sarkar, B. Mukherjee, and B. Tudu, J. Magn. Magn. Mater. 2019, 485, 165-173. DOI:10.1016/j.jmmm.2019.04.058

31. L. Dutta, B.Mukherjee, T.Chakraborty, M.Das, L.Mondal, S.Bhattacharya, R.H.Gaonka, Drug Deliv. 2018, 25, 504-516. DOI:10.1080/10717544.2018.1435749

32. M. Zamani, E. Naderi, M. Aghajanzadeh, M. Naseri, A. Sharafi, and H. Danafar, J. Mol. Liq. 2019, 274, 60-67. DOI:10.1016/j.molliq.2018.10.083

33. S. Jafari, M. B. Tavakoli, A. Zarrabi, Iran J Pharm. Res. 2020, 19, 134-144. DOI:10.22037/IJPR.2020.1101032

\section{Povzetek}

Učinkovito zdravljenje gliomov v medicini še vedno predstavlja izziv. Namen dela je izdelati in ovrednotiti nanostrukture na osnovi lipidov za izboljšano dostavo lomustina v možganske tumorske celice. Poskusne formulacije (LNL) so bile razvite s spremenjeno tehniko hidracije lipidne plasti in njihove značilnosti ovrednotene $\mathrm{z}$ in vitro metodami, ki vključujejo analizo velikosti delcev, površinskega naboja, površinske morfologije, notranje strukture, in vitro nalaganja učinkovine, profil sproščanja učinkovine itd. Protirakavi potencial je bil testiran in vitro na glioma celični liniji C6. Elektronsko-mikroskopska študija je prikazala velikost manj kot $50 \mathrm{~nm}$ za izbrane LNL pri 8.8 \% vključitvi učinkovine $\mathrm{s}$ težnjo po podaljšanem sproščanju učinkovine v obdobju $48 \mathrm{~h}$. Konfokalna mikroskopija je pokazala obsežno internalizacijo izbranih LNL v celice C6. S testom MTT je bilo ugotovljeno, da so LNL bolj citotoksični kot prosta učinkovina in prazni nanonosilci. Izbrani LNL so izkazovali izboljšan farmakokinetični profil v krvi in možganih pri poskusnih modelih miši skupaj z zanemarljivo hemolizo mišjih krvnih celic. Za prenos LNL v klinično uporabo so v prihodnosti upravičene nadaljnje študije.

Except when otherwise noted, articles in this journal are published under the terms and conditions of the Creative Commons Attribution 4.0 International License 